\title{
Propagation of Arizona Cypress through Grafting: A Case Study in Albania (Short Communication)
}

\author{
Gjoke Vuksani $^{1, *}$,Giuseppe Cristiano², Barbara De Lucia ${ }^{2}$ \\ ${ }^{1}$ Department of Horticulture and Landscape Architecture, Agricultural University of Tirana, Albania \\ ${ }^{2}$ Department of Agricultural and Environmental Sciences, University of Bari Aldo Moro, Italy
}

Copyright $\bigcirc 2018$ by authors, all rights reserved. Authors agree that this article remains permanently open access under the terms of the Creative Commons Attribution License 4.0 International License

\begin{abstract}
The grafting of ornamental plants is a relatively new practice in Albania aimed at improving both yields and the environment. Although much information is available on the seedling production of Cupressus spp., whereas few grafting cases have been recorded.This note reports the first grafting of the Arizona cypress ( the scion), which is not well known in Albania, on a local ecotype of Mediterranean cypress (the rootstock). The experiment was carried out in a plastic greenhouse in the Laknas area in February 2016by approach graftage. Five hundred grafted baby plants were grown in controlled conditions ( $\mathrm{T}=22^{\circ} \mathrm{C}$ e UR 90\%). RGR-rootstock (33 $\left.\mathrm{mg} \mathrm{g}^{-1} \mathrm{~d}^{-1}\right)$ was higher than RGR-scion (18 $\left.\mathrm{mg} \mathrm{g}^{-1} \mathrm{~d}^{-1}\right)$. This can be explained by the fact that after grafting, the root system of the plant experiences a slowdown in growth rate because of the crunch of grafting. It is thought to be caused by both components from different species with genetic variation with each other. This great difference, when all growing conditions are the same, can also be explained by the quality of grafting for each plant. At the end of our study, the percentage of grafting compatibility was $87 \%$ in Category A (perfect union).
\end{abstract}

Keywords Conifer, Container Production, Vegetative Multiplication, Ornamental Nursery

\section{Introduction}

The use of vegetative propagation is a key factor in both ornamental and forest tree improvement [1].

Grafting is an ancient, vegetative, asexual plant propagation technique. It is most commonly performed by connecting two plant segments, the shoot piece ('scion') and the root piece ('rootstock') [2]. Grafting of ornamental plants is a relatively new practice in Albania aimed at improving both the yield and the environment. A broad range of classical grafting techniques can be found in Garner [3] (2013): bark grafting is relatively easy and very successful. It can be performed in the spring, only when the bark slips or easily separates from the wood. There is no precise definition of 'graft compatibility'; it generally means the establishment of a successful graft union as well as the extended survival and regular functioning of the grafted plant. Taxonomic affinity is a prerequisite for graft compatibility [4].

The Cupressaceae family [5] includes 21 genera and around 130 species of anemophilous trees and shrubs in the northern and southern hemispheres. In the Mediterranean region, this family is widely represented both by native species, typically in woodland, and by non-native species used for ornamental purposes and in some reforestation programs.

Albania is very rich in terms of flora: it is estimated that there are around 3,200 species of vascular plants and Cupressus spp. are quite widespread.

The true cypresses, genus Cupressus L., are evergreen trees or shrubs native to the warm temperate areas of the Northern Hemisphere. The genus comprises about 15 species distributed throughout the western United States, Mexico, northern Central America, the Mediterranean region, northern Africa, and from southern Asia to Japan [6]

The Mediterranean cypress has two different varieties, which were both known in ancient times: the horizontalis has a broad crown and wide angles between the branches and stems, and the pyramidalis has a conical form and small angles between the branches and stems. $C$. sempervirens L. var. horizontalis(Mill.)Gord.is typical along the Vlora-Saranda coastline in the south, on the open sea gulf of the Ionian Sea [7]. It is also spontaneous in the Kruja area (in north central Albania) as well as in the Shkodra region (Balkans region) where it was introduced and grows mainly in the skeletal lands of Shiroka and along the Shkoder-Hani i Hotit road [8]. This species is tolerant to calcareous, clayish, dry and poor soils [9] and is generally considered suitable for marginal and sub-marginal sites. This variety is propagated by seeds or cuttings [10]. 
Arizona cypress (C. arizonica Green), referred to as $C$. glabra by some botanists, has shown promising characteristics for afforestation in both arid and semi-arid areas $[11,12]$. It is a medium-sized evergreen tree with a conic to ovoid-conic crown [13] growing in the mountains of Arizona to Mexico between the altitudes of $1300-2500 \mathrm{~m}$ asl and tolerates temperatures from $-15^{\circ} \mathrm{C}$ to $40^{\circ} \mathrm{C}$. It was introduced into Europe in the early 1900s, where it is used as an ornamental plant and as a forest species. This species.The aromatic foliage, pyramidal shape, attractive blue-green or gray-green foliage with a pleasant characteristic smell and excellent drought tolerance [14] make it a good evergreen landscaping candidate for areas in European hardiness zones from 7 to 9.

In Albania, the Arizona cypress was introduced in the last few years as an ornamental tree in public and private urban green spaces and is much in demand. The seed usually germinates within $1-2$ months at $20^{\circ} \mathrm{C}$; and cutting propagation is possible: withApril-May being the best time to take cuttings. The rooting of stem cuttings of 'Carolina Sapphire' is possible at all growth stages; however softwood cuttings seem to be more difficult to root. Difficulties encountered when rooting softwood cuttings suggest that propagators should root cuttings during the semi-hardwood or hardwood stages. Cuttings or a side-veneer graft can be used to propagate this species [15].

There is considerable information available regarding the seedling production of Cupressus spp. [16], but little information on grafting.

The main advantages of the cypress genus graft are: mass production of selected genotypes; suitable for ornamental and wind-break plantings; good compatibility between grafted clone and rootstock from seeds; no significant effect of the rootstock on the growth rate, shape, foliage colour, resistance of scions. Menerve and Istas [17] (1975) highlighted the satisfactory graft compatibility of Cupressusarizonica var. glabra 'Conica' on Pinusorientalis, and poor survival for $C$. arizonica var. glabra 'Conica' on Thujaoccidentalis and T. plicata.

This note reports the first grafting of the Arizona cypress, which is little known in Albania, onto an Albanian ecotype of the Mediterranean cypress $(C$. sempervirens L. var. horizontalis (Mill.) Gord.).

\section{Propagating Cypress by Grafting:Procedure}

The experiment was carried out in an ornamental nursery, in a plastic greenhouse in the area of Laknas $\left(41^{\circ} 22^{\prime} 36^{\prime \prime} \mathrm{N}\right.$, $19^{\circ} 44^{\prime} 14^{\prime \prime}$ E, Tirana, Albania).

2.1 Rootstock preparation: is made from one year old Mediterranean cypress seedlings produced by seeds harvested from natural plants of Kruja region (AL).Cypress were grown in pots filled with a mixture of peat and perlite (3:1).). The thickness of the rootstock was slightly thicker than $1 \mathrm{~cm}$. The length of the bark cut was $1.5-2.5 \mathrm{~cm}$ (Fig.1A).

2.2 Scion preparation: is made by taking the grown tops with a length of $10-15 \mathrm{~cm}$ from young $C$. arizonica plants were individually transplanted in $30 \mathrm{~cm}$ diameter containers filled with a handmade mix of Thumanestorfe (Albania) base and perlite (Fig.1B).
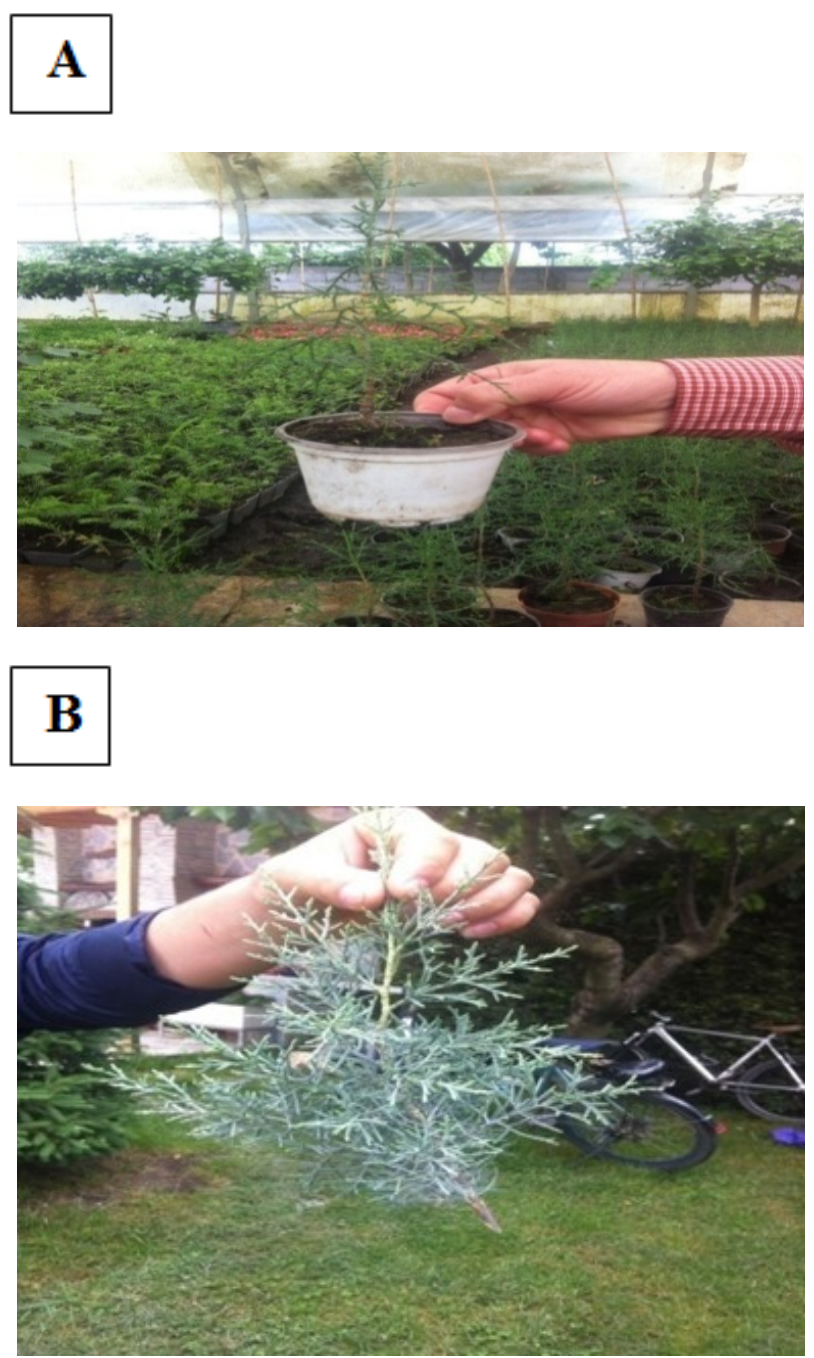

Figure 1. Part A: Potted Mediterranean cypressseedling; Part B: Potted Arizona cypress

2.3 Grafting method: is successfully carried out by approach graftage. The grafting was carried out on 15 February 2016 at Laknas near the city of Tirana (Al). In order to obtain a better contact between the rootstock and the graft, the grafted point was tied down to raffia of the tropical palm bark: Sagustaedinera. Five hundred grafted baby plants were grown in controlled conditions $\left(\mathrm{T}=22^{\circ} \mathrm{C}\right.$ e UR 90\%).

2.4 Growth measurements: has been performed to evaluate the progress of grafting of Arizona Cypress over Mediterranean Cypress. The growth measurements on grafted plants were carried out in the laboratory of the Horticulture and Landscape Architecture Department of 
University of Tirana on May 15 (DAG 90), July 15 (DAG 150) and September 15 (DAG 210), respectively. The following bio-morphological parameters were measured on the scion: plant height $(\mathrm{cm})$, leaves $(\mathrm{n})$, above ground fresh and dry weight $(\mathrm{g})$ : shoots were air-dried and then placed in an oven at $\mathrm{T}=70^{\circ} \mathrm{C}$. Ten plants were sampled. Both ground fresh and dry weight $(\mathrm{g})$ of the rootstock were measured.

Calculation of growth index RGR: RGR was calculated using dry weight data, according to Hunt [18] (1978). Relative rate of growth (RGR), which reflects the ability of the plant to produce new dry matter in a specific period of time, was calculated as follows:

$\mathrm{RGR}=\mathrm{d}_{\mathrm{W}} / \mathrm{W} * 1 / \mathrm{dt} ;$ in $\mathrm{mg} \mathrm{g}^{-1} \mathrm{day}^{-1}$

$\mathrm{W}=$ dry weight of sample $\mathrm{dt}=\mathrm{d} 2-\mathrm{d} 1$ is the interval of time between samples of measure.

The Relative Growth Rates (RGR; $\mathrm{g} \mathrm{g}^{-1}$ day $^{-1}$ ) as a change in biomass per unit, of initial biomass per unit time ((lnDMPlant2-lnDMPlant1)/(t2-t1)), were calculated for the growth period DAG 210 (post Grafting ), [19] RGR were exposed separately for the whole plant (RGR-Plant), scion (RGRScion) and root system (RGR rootstock).[20] At the end of the experiment (DAG 210), the percentage of the grafting compatibility was calculated.

\section{Results}

From measurements of bio-morphological parameters on the scion, performed in three consecutive measurements, from May 15 (DAG 90), July 15 (DAG 150) and September 15 (DAG 210), respectively, appears fairly clearly (Figure 2), that regarding the scion, the height trend was increased from $29.4 \mathrm{~cm}$ (DAG 90) to 39.4 (DAG 210), with an increase of $34 \%$. The same trend was observed for the number of leaves (Figure 3): the values were between 15 (DAG 90) and 29 (DAG 210) with an increase of 97\%. The above values for the height of grafted plants as well as the density of its crown (number of leaves )are very satisfactory, which indicates that the crops will have a good merchandise value.

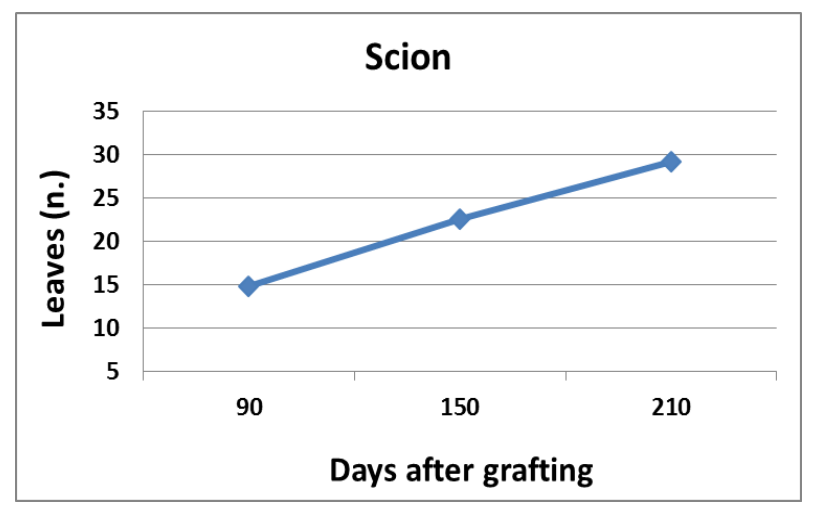

Figure 2. Scion canopy height (Arizona cypress) trend after 90, 150 and 210 DAG in grafted plant.

Regarding the fresh weight (Figure 4), different trends between scion and rootstock were recorded . In fact, while with the scion, the greatest increase occurred in the period between DAG 90 and DAG 150 ( $70 \%$ of the total increase), with the rootstock, $80 \%$ of the total increase occurred in the period between DAG 150 and DAG 210.

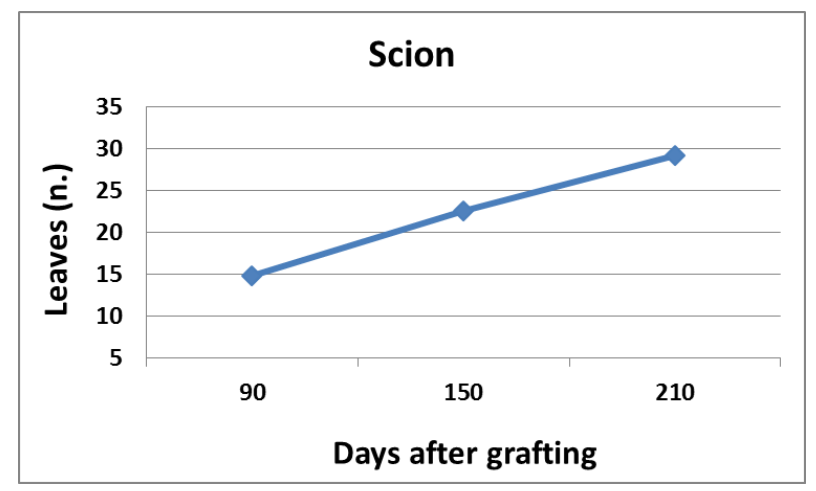

Figure 3. Scion leaves (Arizona cypress) trend after 90, 150 and 210 DAG in grafted plant.

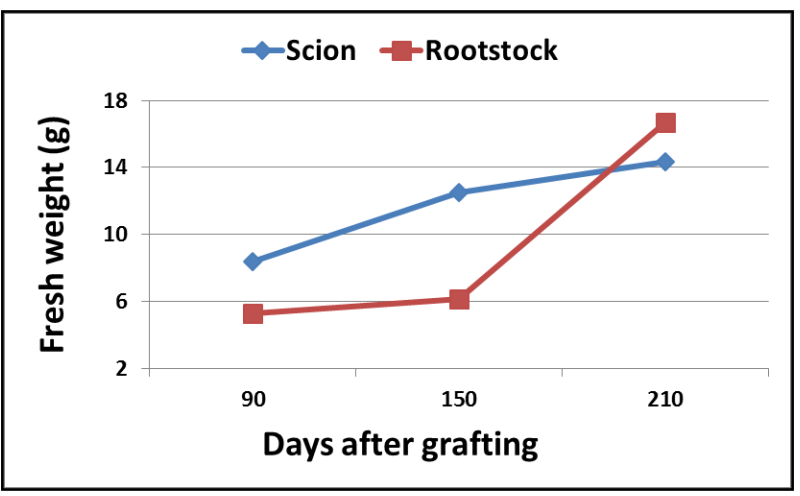

Figure 4. Comparison of the fresh weight trend in both scion (Arizona cypress) and rootstock (Mediterranean cypress) after 90, 150 and 210 DAG in grafted plant.

The relative growth rates (RGR; $\mathrm{mg} \mathrm{g}^{-1} \mathrm{~d}^{-1}$ ), as a change in biomass per unit, of initial biomass per unit time, was calculated for the growth period, DAG 210 (post Grafting). As it is clearly seen in the graphs below (Figure 5.0), the RGR-rootstock ( $33 \mathrm{mg} \mathrm{g}^{-1} \mathrm{~d}^{-1}$ ) was higher than RGR- scion (18 $\left.\mathrm{mg} \mathrm{g}^{-1} \mathrm{~d}^{-1}\right)$. This fact can be explained, that after grafting the relative growth rates of Rootstock (RGR-rst), it was grown far more than RGR- scion. It is thought to be caused by both components from different species with genetic variation with each other. This major change in relative growth rates at rootstock compared to scion, is not welcome because it has resulted in the production of grafted plants with differences in their vegetative development. This slowdown, in the relative growth rates of RGR-sc, which is observed in the scion, should be followed even after this time (DAG 201), so as not to induce disproportionate development of the grafted plant and result in graft failure. This will be a goal of our ongoing research work.

But, relative growth rate of whole dry weight of plant (RGR-Plant), is the central parameter in plant growth 
analysis [19]. From our data, we can see that RGR-Plant is $25 \mathrm{mg} \mathrm{g}^{-1} \mathrm{~d}^{-1}$ smaller than that RGR-rootstock, and larger than RGR-twig since both components affect this parameter.

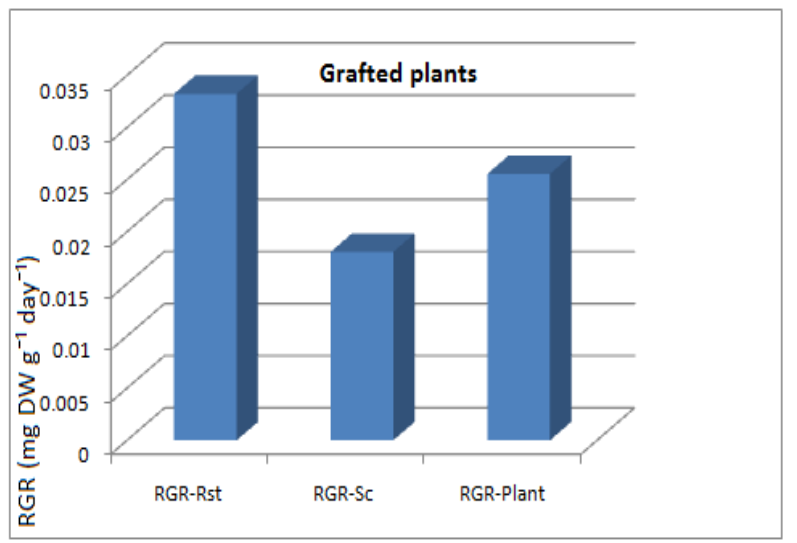

Figure 5.1. Relative growth rates of whole dry weight of plant (RGR-Plant) based on dry weight in scion and rootstock.

RGR-plant is an important parameter in plant growth analysis. For this reason, it was calculated the rational growth rate of RGR-Plant, for each of the 10 plants, that were measured the bio-morphological parameters in progress. The data obtained shows that there is a large variation in growth rates (RGR-plant) of each plant from $56 \mathrm{mg} \mathrm{g}^{-1} \mathrm{~d}^{-1}$ to $13 \mathrm{mg} \mathrm{g}^{-1} \mathrm{~d}^{-1}$

This great difference, when all growing conditions are the same, can be explained by the quality of grafting for each plant. Different plants with different thicknesses of rootstock and scion, and for more that everything is performed by the human hand, grafting is not identical to each plant.

Therefore, we strongly recommend that specialists who do grafting, should have a lot of experience and also we recommend that the scion and rootstock should have similar consistency, to match satisfactorily.

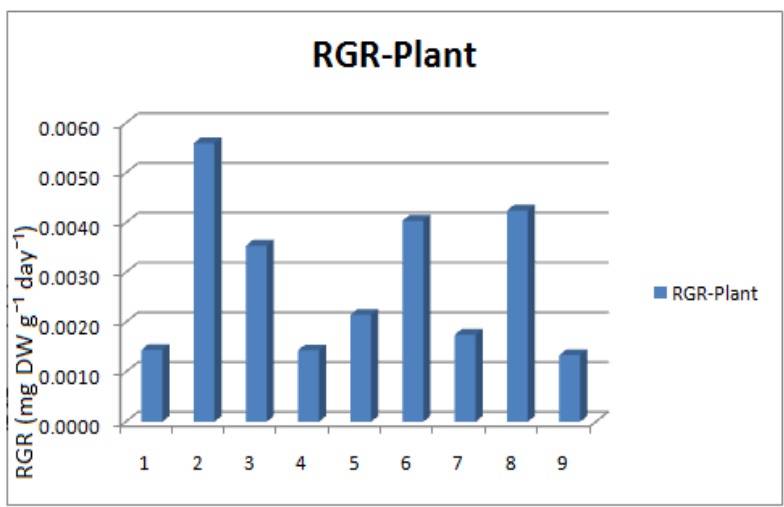

Figure 5.2. Relative growth rates (RGR, mg g-1 d-1) based on the dry weight of whole plant, RGR-plant per 10 plants that were measured .

At the end of our experiment (Figures 6-7), the percentage grafting compatibility was $87 \%$ in Category A (perfect union), $3 \%$ in Category B (good union), $1.4 \%$ in Category $\mathrm{C}$ (union with discontinuities in the bark), 2.6\% in Category $\mathrm{D}$ (union with vascular discontinuities), and $6 \%$ in Category E (breakage of the the graft union was observed in the nursery)

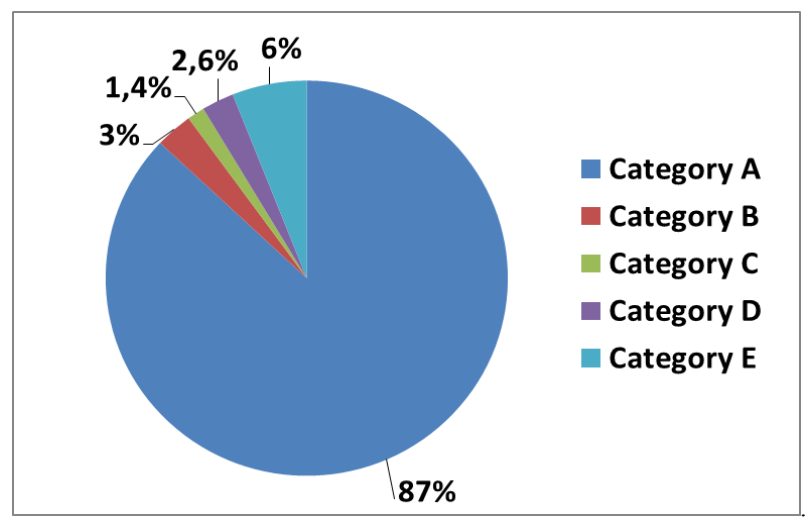

Figure 6. Compatibility of the graft union between Arizona cypress and Mediterranean cypress rootstock

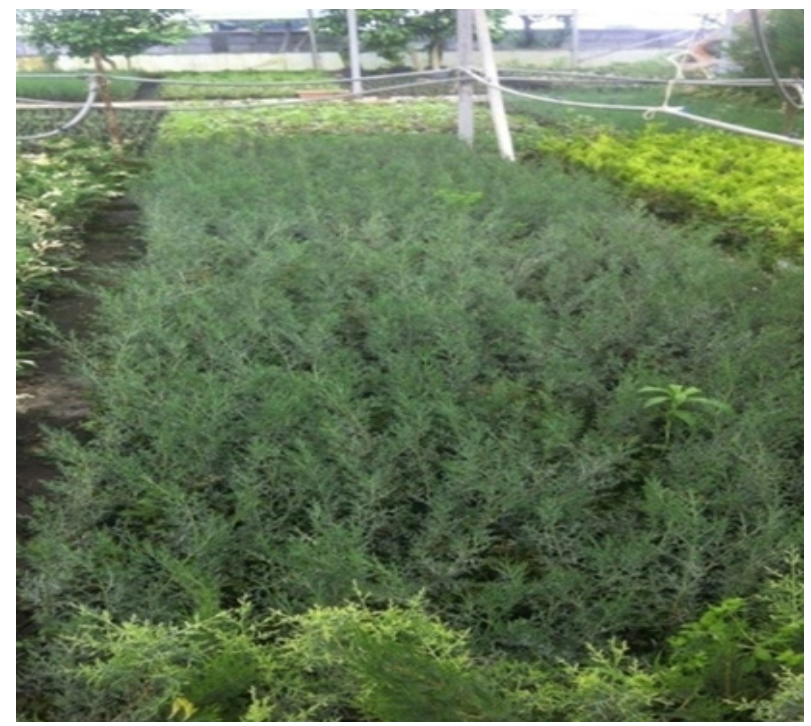

Figure 7. Grafted plants of Arizona cypress 210 DAG after grafting

\section{Conclusions}

In order to meet future challenges in relation to the growing demand for superior ornamental planting material, it is important to develop suitable methods for the rapid propagation of selected clones. The propagation with approach graftage of the scion of $C$. arizonica on the $C$. sempervirens rootstock was successful for the production of quality plants in Albania. Results showed that 435 strong plants were available to be planted in the permanent place with an $87 \%$ successfully grafted.

We strongly recommend that specialists who do grafting, should have a lot of experience and also that the scion and rootstock should have similar consistency, to match 
satisfactorily.

\section{REFERENCES}

[1] B. Zobel, J. Talbert. Applied forest tree improvement. John Wiley and Sons Inc., New York, USA, 1984.

[2] H.T. Hartmann, D.E. Kester, F.T. Davies , R.L.Geneve. Plant Propagation: Principles and Practices. 7th ed. Prentice Hall. Upper Saddle River, NJ, 2002.

[3] R. J. Garner. The Grafter's Handbook, 6 thEdn London: Octopus Publishing Group, 2013.

[4] E. E. Goldschmidt. Plant grafting: new mechanisms, evolutionary implications. Frontiers in plant science, 5, 727, 2014.

[5] C. Schulz, P. Knopf, T. H. Stützel. Identification key to the Cypress family (Cupressaceae). FeddesRepertorium: ZeitschriftfürbotanischeTaxonomie und Geobotanik, $116(1$ - 2), 96-146. 2005.

[6] M. Ducrey, G. Brofas, C. Andreoli, P. Raddi. Genus Cupressus. Cypress: A practical handbook, 9-25, 1999.

[7] R. Koçi, A. Imeri, A. Çaushi Flora situation in South-Western part of Vlora Bay, Albania. Journal of International Academic Research for Multidisciplinary, Vol. 6, Issue 2, March 2018.

[8] G. Vuksani.Luletari fq.448-449."Geer Editors", 2004.

[9] S. Xenopoulos, C. Andreoli, A. Panconesi, J. Pinto Ganhao, J.J. Tuset. Importance of Cypress. In: Progress in EEC Research on Cypress Diseases, Commission of the European Communities, Report EUR 12493, 1-13, 1990.
[10] M. A. Dirr, C. W. Heuser. The reference manual of woody plant propagation: from seed to tissue culture (No. 634.96702 D5). Athens, GA: Varsity Press., 1987.

[11] R.V. Long. Desert Forestry Potential in Nevada-Phase I. In: Proc. 29th Annual Meeting Forestry Committee Great Plains Agricultural Council. Albuquerque, N. M., USA, pp 95-110, 1977.

[12] A. Farjon. A Handbook of the World's Conifers. Koninklijke Brill, Leiden, 2010.

[13] F. H. Elmore. Shrubs and trees of the southwest uplands(No. 19). Western National Parks Association, 1976.

[14] E. F. Gilman, D. G. Watson. Cupressusarizonica var. arizonicaENH381 website at http://edis.ifas.ufl.edu. 2014

[15] H. L. Stubbs, S. L. Warren, F. A. Blazich, T. G. Ranney. Nitrogen nutrition of containerized Cupressusarizonica var. glabra 'Carolina Sapphire'. Journal of Environmental Horticulture, 15(2), 80-83, 1997.

[16] P. Kostopoulou, K. Radoglou, O. Dini-Papanastasi, G. Spyroglou. Enhancing planting stock quality of Italian cypress (Cupressussempervirens L.) by pre-cultivation in mini-plugs. Ecological engineering, 36(7), 912-919, 2010.

[17] I. Menerve, W. Istas. Conifer grafting trial. Revue de l'Agriculture, 28(4), 829-844, 1975.

[18] R.Hunt. Plant Growth Analysis. (Studies in Biology, 96), Edward Arnold, London, 1978.

[19] R. Hunt, D. R. Causton, B. ShipleY, and A. P. AskewA Modern Tool for Classical Plant Growth Analysis , 2002.

[20] G. Sallaku, H. Sandén, I. Babaj, S. Kaciu, A. Balliu, and B. Rewald. Specific nutrient absorption rates of transplanted cucumber seedlings are highly related to RGR and influenced by grafting method, AMF inoculation and salinity. ScientiaHorticulturae, 243, 177-188, 2019. 